\title{
Depressive symptoms in Parkinson's disease and in non-neurological medical illnesses
}

\author{
This article was published in the following Dove Press journal: \\ Neuropsychiatric Disease and Treatment \\ 20 March 2013 \\ Number of times this article has been viewed
}

\author{
Francesca Assogna' \\ Sabrina Fagioli' \\ Luca Cravello' \\ Giuseppe Meco² \\ Mariangela Pierantozzi ${ }^{3}$ \\ Alessandro Stefani ${ }^{3}$ \\ Francesca Imperiale ${ }^{2}$ \\ Carlo Caltagirone ${ }^{1,3}$ \\ Francesco E Pontieri ${ }^{4}$ \\ Gianfranco Spalletta' \\ II.R.C.C.S. Santa Lucia Foundation, \\ Rome, Italy; ${ }^{2}$ Department of \\ Neurology and Psychiatry (Parkinson's \\ Centre) and Research Centre of \\ Social Diseases (CIMS), University \\ "Sapienza", Rome, Italy; ${ }^{3}$ Department \\ of Neuroscience, University "Tor \\ Vergata", Rome, Italy; ${ }^{4}$ Department \\ of Neuroscience, Mental Health \\ and Sensory Systems, University \\ "Sapienza", Movement Disorder Unit, \\ Sant'Andrea Hospital, Rome, Italy
}

Correspondence: Gianfranco Spalletta Laboratory of Clinical and Behavioral Neurology, I.R.C.C.S. Santa Lucia

Foundation, Via Ardeatina, $306-00179$

Rome, Italy

Tel +3906 5 I50 I575

Fax +3906 51501575

Email g.spalletta@hsantalucia.it
Background: Patients with neurological and non-neurological medical illnesses very often complain of depressive symptoms that are associated with cognitive and functional impairments. We compared the profile of depressive symptoms in Parkinson's disease (PD) patients with that of control subjects (CS) suffering from non-neurological medical illnesses.

Methods: One-hundred PD patients and $100 \mathrm{CS}$ were submitted to a structured clinical interview for identification of major depressive disorder (MDD) and minor depressive disorder (MIND), according to the Diagnostic and Statistical Manual of Mental Disorders, 4th edition, text revision (DSM-IV-TR), criteria. The Hamilton Depression Rating Scale (HDRS) and the Beck Depression Inventory (BDI) were also administered to measure depression severity.

Results: When considering the whole groups, there were no differences in depressive symptom frequency between PD and CS apart from worthlessness/guilt, and changes in appetite reduced rates in PD. Further, total scores and psychic and somatic subscores of HDRS and BDI did not differ between PD and CS. After we separated PD and CS in those with MDD, MIND, and no depression (NODEP), comparing total scores and psychic/somatic subscores of HDRS and BDI, we found increased total depression severity in NODEP PD and reduced severity of the psychic symptoms of depression in MDD PD, with no differences in MIND. However, the severity of individual symptom frequency of depression was not different between PD and CS in MDD, MIND, and NODEP groups.

Conclusion: Although MDD and MIND phenomenology in PD may be very similar to that of CS with non-neurological medical illnesses, neurological symptoms of PD may worsen (or confound) depression severity in patients with no formal/structured DSM-IV-TR, diagnosis of depressive mood disorders. Thus, a thorough assessment of depression in PD should take into consideration the different impacts of neurological manifestations on MDD, MIND, and NODEP.

Keywords: Parkinson's disease, neuropsychiatry, depression, nonmotor symptoms

\section{Introduction}

Depression is one of the most common complications in Parkinson's disease (PD) and is well known for having a major impact on the prognosis ${ }^{1-5}$ and upon patient and carer quality of life. ${ }^{6-8}$ However, whether the phenomenology of depression in $\mathrm{PD}$ is similar to the phenomenology of depression among individuals with other non-neurological diseases is still unclear, especially concerning the hypothesis that depressive symptoms might reflect a reaction to a chronic disabling condition or may be worsened by neurological symptoms.

Many authors have previously addressed the question about whether depression in PD is characterized by specific symptoms that distinguish it from depression in non-PD patients. For instance, by comparing the depressive symptoms of PD patients with those 
of matched patients with other chronic disabling illnesses, Ehmann et $\mathrm{al}^{9}$ found that the symptoms of PD patients were more severe than those of disabled control subjects (CS). On the other hand, several studies showed that the depressive profile of PD patients does not significantly differ from that of non-PD subjects. ${ }^{10,11}$ In addition, Lieberman ${ }^{12}$ showed that depression in PD seems to be characterized by the relative absence of symptoms such as guilt, sorrow, and suicidal ideation, which are traditionally symptoms of depression in non-PD subjects.

All these studies employed different control groups and measures of depression; thus, a rather contradictory picture emerges. Moreover, the vast majority of these studies lack a homogeneous set of criteria for diagnosing depression in PD.

There is much debate about the most valid strategy to diagnose depression in PD. ${ }^{13-16}$ One of the major problems concerns the core cognitive-somatic feature of depression (ie, symptoms of difficulty in concentrating, loss of energy, psychomotor retardation, hypomimia, fatigue, apathy), which may be present in PD patients with no depressive mood disorder diagnosis. ${ }^{3,12,14,17,18}$

Nowadays, in the absence of specific screening tools, the conventional approach for establishing the diagnosis of depressive disorder in PD patients is based on the Diagnostic and Statistical Manual of Mental Disorders. ${ }^{19-21}$ In particular, the National Institute of Neurological Disorders and Stroke (NINDS)/National Institute of Mental Health (NIMH) Work Group proposed provisional diagnostic criteria for depression in $\mathrm{PD}^{13}$ using an inclusive approach: ie, by considering all symptoms as related to depression, regardless of their overlap with PD or other medical conditions, ${ }^{13}$ and conducting depression assessments at a consistent time and during an "on" state, in order to avoid a negative reporting or assessment bias. ${ }^{13,22}$

Given these considerations, the primary aim of this study was to extend findings of previous research about whether the phenomenology of depression in PD is qualitatively different from that of subjects with other disabling nonneurological medical illnesses. In particular, we addressed previous methodological flaws by comparing a sample of PD outpatients under stable dopaminergic therapy during an "on" state with a group of CS referred to an outpatient clinic for medical illnesses. Here, we adopted the diagnostic criteria developed by the NINDS/NIMH Work Group to diagnose depression in PD. Moreover, we analyzed the extent of overlap between symptoms of PD and symptoms of depression by comparing the depressive phenomenology of PD with CS separately in groups with a diagnosis of major depressive disorder (MDD), minor depressive disorder (MIND), or no depression (NODEP).

\section{Methods}

\section{Participants}

The study was carried out on 100 subjects diagnosed as having idiopathic PD according to international guidelines. ${ }^{23} \mathrm{PD}$ patients were recruited at the outpatient services for movement disorders of three institutions (Department of Neuroscience, Mental Health and Sensory Systems, University "Sapienza", Sant'Andrea Hospital, Rome, Italy; Department of Neurology and Psychiatry, Umberto I General Hospital, Rome Italy; and Department of Neuroscience, University "Tor Vergata", Rome, Italy) and compared with 100 CS matched for age, gender, educational attainment, and global cognitive level. CS suffered from medical illnesses, but not neurological diseases, were enrolled at the outpatient clinic of the IRCCS Santa Lucia Foundation, Rome, Italy, and were under stable pharmacological therapy. Medical illnesses of CS enrolled in the study were hypertension (62\%), arthritis (26\%), chronic obstructive pulmonary disease $(24 \%)$, coronary artery disease (22\%), diabetes mellitus (18\%), cataract (14\%), gastrointestinal disease $(9 \%)$, osteoporosis $(7 \%)$, hypothyroidism $(6 \%)$, gout $(6 \%)$, and urinary disease (4\%). Common inclusion criteria for PD patients and CS were the following: (1) vision and hearing sufficient for compliance with testing procedure, (2) MiniMental State Examination score $\geq 25,{ }^{24}$ and (3) no dementia according to the Diagnostic and Statistical Manual of Mental Disorders, 4 th edition, text revision (DSM-IV-TR), criteria. $^{19}$

Common exclusion criteria were: (1) the presence of major nonstabilized medical illnesses (nonstabilized diabetes; nonstabilized obstructive pulmonary disease or asthma; hematologic/oncologic disorders; vitamin B12 or folate deficiency; pernicious anemia; clinically significant and unstable active gastrointestinal, renal, hepatic, endocrine, or cardiovascular disorders; and recently treated hypothyroidism); (2) known or suspected history of alcoholism, drug dependence and abuse, head trauma, and mental disorders (apart from mood or anxiety disorders), according to the DSM-IV-TR criteria; ${ }^{19}$ and (3) presence of vascular brain lesions, brain tumor, and/or marked cortical and subcortical atrophy on computed tomography and/or magnetic resonance imagery scan. A specific exclusion criterion for PD patients was an unclear history of chronic dopaminergic treatment responsiveness. The PD patients enrolled in the study have been under stable dopaminergic therapy for at least 2 months and did not require booster doses of L-dopa or dopamine agonists. 
Clinical evaluation of motor symptoms was made using the Unified Parkinson's Disease Rating Scale - Part III (UPDRS-III). ${ }^{25,26}$ All testing and clinical evaluations were carried out 2 hours after the PD patients had received their first daily dose of medication, during the "on" states, from trained specialists who were blind to the aims of the study. Evaluation of inter-rater reliability in this study was in the excellent to good range for clinical and psychopathological scales used, with intraclass correlations ranging from 0.80 to 0.93 .

The study was approved by the Santa Lucia Foundation Ethical Committee, and, in accordance with the Helsinki Declaration, each subject signed an informed consent form prior to enrolment.

\section{Clinical and psychopathological evaluation}

Sociodemographic data were collected by the neurologist during the clinical examination. Clinical characteristics, such as age of onset of first symptoms and duration of illness in years, were also assessed. Global cognitive performance was evaluated with the Mini-Mental State Examination. ${ }^{24}$

Quantification of depressive symptom severity was evaluated with the Beck Depression Inventory (BDI) ${ }^{27}$ and the Hamilton Depression Rating Scale-17 items (HDRS). ${ }^{28}$ According to Leentjens et al, ${ }^{21}$ in this study the HDRS and the BDI were used to measure symptom severity and not as diagnostic scales; for the statistical analyses, we considered both the psychic (PSY) and somatic (SOM) subscores of these scales in order to distinguish the possible differences between the two dimensions of depression. ${ }^{29-31}$

All PD and CS underwent the structured clinical interview for DSM-IV-TR, patient edition, ${ }^{32}$ for the identification of MDD and MIND according to the DSM-IV-TR criteria. ${ }^{19}$ Only symptoms that contributed to cause clinically significant impairment in important areas of functioning, such as social, occupational, or other, in accordance with Criterion $\mathrm{C}$ of Major Depressive Episode of the DSM-IV-TR, were scored as present. We adopted an inclusive approach (in accordance with the NINDS/NIMH Work Group for depression in PD) that considers all symptoms as related to depression, regardless of their overlap with PD or other medical conditions. ${ }^{13}$ In each PD patient or CS, the presence of individual depressive symptoms was rated using the structured clinical interview for DSM-IV-TR, patient edition.

\section{Statistical analysis}

Comparisons between PD and CS groups for age and educational attainment were performed using the $t$-test. Difference in frequency of the individual depressive symptoms between males and females was tested using the $\chi^{2}$ test. To determine the significance of correlations between continuous variables, correlation analyses and Fisher's $r$ to $z$ transformation were performed.

Independent $t$-tests were used to compare differences between PD and CS groups on the HDRS and BDI total score and PSY and SOM subscores. We used a statistical model corrected for multiple comparisons according to the Bonferroni procedure ( $P<0.05 /$ number of comparisons $)$ to minimize the likelihood of type I (false positive) errors. In particular, the level of statistical significance was defined as $P<0.0028$ ( $P<0.05 / 18$ comparisons - see Tables 1 and 3$)$ for individual depressive symptom frequency comparisons between PD and CS considered either as whole groups or as a function of the depression category, and $P<0.0028$ $(P<0.05 / 18$ comparisons - see Table 2$)$ for measuring significant differences in HDRS and BDI scores between $\mathrm{PD}$ and $\mathrm{CS}$.

\section{Results}

\section{Comparisons of PD and CS considered as whole groups}

Table 1 shows the sociodemographic and clinical characteristics of the study populations. As expected from the matching procedure, the PD and CS groups did not differ significantly for age, gender, educational attainment, and global cognitive level.

After the correction for multiple comparisons, the two groups did not significantly differ in any total scores and PSY and SOM subscores of HDRS or BDI.

Further, we found that PD patients reported significantly lower frequency of the individual depressive symptoms "changes in appetite" and "worthlessness/guilt" than CS (Table 1).

An exploratory analysis investigating the possible differences between PD and CS groups in the total number of DSM-IV-TR depressive symptoms showed no difference between the PD group (mean \pm standard deviation $[\mathrm{SD}]=2.6 \pm 1.6)$ and the $\mathrm{CS}$ group $($ mean $\pm \mathrm{SD}=3.1 \pm 2.2)$ $(t=1.808 ; \mathrm{df}=198 ; P=0.0722)$.

\section{Comparisons of PD and CS in function of category of MDD, MIND, and NODEP}

When considering differences between the two PD and CS groups on the scores of HDRS and BDI as a function of the category of depression (ie, separately for MDD, MIND, and NODEP groups), after the correction for multiple comparisons, as shown in Table 2, the two depression rating scales 
Table I Sociodemographic and clinical characteristics of 100 PD patients and I00 CS

\begin{tabular}{|c|c|c|c|c|c|}
\hline \multirow[t]{2}{*}{ Characteristics } & \multicolumn{2}{|c|}{ Mean (SD) } & \multirow[t]{2}{*}{$t$} & \multirow[t]{2}{*}{ df } & \multirow{2}{*}{$\begin{array}{l}P \\
\text { uncorrected }\end{array}$} \\
\hline & PD & CS & & & \\
\hline Age (years) & $71.2(5.9)$ & $72.4(5.1)$ & 1.616 & 198 & 0.108 \\
\hline Age at onset of symptoms (years) & $64.2(8.7)$ & & & & \\
\hline Duration of illness (years) & $7.0(6.7)$ & & & & \\
\hline Education (years) & $9.1(4.8)$ & $8.5(4.7)$ & -0.887 & 198 & 0.3764 \\
\hline UPDRS-III & $26(14.0)$ & & & & \\
\hline MMSE score & $27.1(2.5)$ & $27.6(2.5)$ & 1.189 & 198 & 0.2360 \\
\hline HDRS total score & $9.6(4.7)$ & $10.4(7.0)$ & 1.006 & 198 & 0.3155 \\
\hline HDRS psychic score & $3.3(2.3)$ & $4.1(3.0)$ & 2.139 & 198 & 0.0337 \\
\hline HDRS somatic score & $6.1(2.8)$ & $6.2(4.5)$ & 0.038 & 198 & 0.9697 \\
\hline BDI total score & $12.2(7.0)$ & $13.6(10.4)$ & 1.137 & 198 & 0.2570 \\
\hline BDI psychic score & $6.1(4.7)$ & $7.7(6.3)$ & 1.940 & 198 & 0.0538 \\
\hline \multirow[t]{2}{*}{ BDI somatic score } & $6.0(3.2)$ & $5.9(4.7)$ & -0.160 & 198 & 0.8731 \\
\hline & n & n & $\chi^{2}$ & df & $\begin{array}{l}P \\
\text { uncorrected }\end{array}$ \\
\hline Gender (male) & 46 & 46 & & & \\
\hline MDD & 15 & 27 & 4.524 & 2 & 0.1041 \\
\hline MIND & 39 & 36 & & & \\
\hline NODEP & 46 & 37 & & & \\
\hline Sad mood & 48 & 58 & 2.007 & I & 0.1566 \\
\hline Loss of interest/pleasure & 22 & 40 & 7.574 & I & 0.0059 \\
\hline Changes in weight & 7 & 15 & 3.269 & I & 0.0706 \\
\hline Changes in appetite & 2 & 14 & 9.783 & I & $0.0018^{*}$ \\
\hline Changes in weight/changes in appetite (total) & 9 & 18 & 3.468 & I & 0.0626 \\
\hline Early insomnia & 26 & 42 & 5.704 & I & 0.0169 \\
\hline Middle insomnia & 41 & 58 & 5.781 & I & 0.0162 \\
\hline Late insomnia & 34 & 51 & 5.913 & I & 0.0150 \\
\hline Insomnia (total) & 45 & 60 & 4.511 & I & 0.0337 \\
\hline Agitation & 0 & 2 & 2.020 & I & 0.1552 \\
\hline Slowness & 7 & 1 & 4.688 & I & 0.0304 \\
\hline Agitation/slowness (total) & 7 & 3 & 1.684 & I & 0.1944 \\
\hline Loss of energy & 79 & 71 & $\mathrm{I} .707$ & I & 0.1914 \\
\hline Worthlessness/guilt & 8 & 24 & 9.524 & I & $0.0020 *$ \\
\hline Concentration deficits & 15 & 13 & 0.166 & I & 0.6836 \\
\hline Decisional incapability & 28 & 26 & 0.101 & I & $0.750 \mathrm{I}$ \\
\hline Concentration/decision (total) & 39 & 34 & 0.539 & I & 0.4627 \\
\hline Suicide ideation & 2 & 0 & 2.020 & I & 0.1552 \\
\hline
\end{tabular}

Notes: *Statistically significant differences after Bonferroni correction for multiple comparisons ( $P<0.05 / 18$ comparisons). The nine symptoms of MDD and MIND according to the Diagnostic and Statistical Manual of Mental Disorders, 4th edition, text revision, criteria are shown in bold.

Abbreviations: BDI, Beck Depression Inventory; CS, control subjects; df, degrees of freedom; HDRS, Hamilton Depression Rating Scale; MDD, major depressive disorder; MIND, minor depressive disorder; MMSE, Mini-Mental State Examination; NODEP, no depression; PD, Parkinson's disease; SD, standard deviation; UPDRS-III, Unified Parkinson's Disease Rating Scale - Part III.

described a quite coherent picture. Both HDRS and BDI highlighted an increased level of total and SOM scores of depression in NODEP PD patients in comparison with NODEP CS. Further, severity scores of the two scales did not differ in MIND patients. The only inhomogeneous result between the two depression rating scales was found in the PSY subscore. Indeed, the HDRS described reduced severity of PSY subscore in MDD PD patients, whereas the BDI described increased severity of PSY subscore in NODEP PD patients (Table 2).

An exploratory analysis of the total number of DSMIV-TR depressive symptoms in PD and CS groups, considered separately in the different depression categories, showed significant differences between MDD PD patients (mean $\pm \mathrm{SD}=5.1 \pm 0.9)$ and MDD CS (mean $\pm \mathrm{SD}=$ $5.9 \pm 0.8)(t=2.614 ; \mathrm{df}=40 ; P=0.0126)$ and between NODEP PD patients (mean $\pm \mathrm{SD}=1.2 \pm 0.9$ ) and NODEP CS (mean $\pm \mathrm{SD}=0.7 \pm 0.7)(t=-2.783 ; \mathrm{df}=81$; $P=0.0067)$. On the contrary, no significant difference was found between MIND PD (mean $\pm \mathrm{SD}=3.2 \pm 0.7$ ) and MIND CS (mean $\pm \mathrm{SD}=3.4 \pm 0.6)(t=1.402 ; \mathrm{df}=73$; $P=0.1651)$.

Furthermore, when we considered the frequency of individual depressive symptoms separately in MDD, MIND, and NODEP patients, no difference was found between PD and CS (Table 3). 
Table 2 Total, psychic, and somatic scores of HDRS and BDI in MDD, MIND, and NODEP PD patients and CS

\begin{tabular}{|c|c|c|c|c|}
\hline \multirow[t]{2}{*}{ Variables } & \multicolumn{2}{|c|}{ Mean (SD) } & \multirow[t]{2}{*}{$t$} & \multirow{2}{*}{$\begin{array}{l}P \\
\text { uncorrecte }\end{array}$} \\
\hline & PD & CS & & \\
\hline \multicolumn{5}{|l|}{ HDRS } \\
\hline \multicolumn{5}{|c|}{ Psychic score } \\
\hline MDD & $6.0(1.8)$ & $7.5(1.0)$ & 3.459 & $0.0013^{*}$ \\
\hline MIND & 4.7 (I.5) & $5.1(I . I)$ & 1.353 & 0.1801 \\
\hline NODEP & $1.3(1.0)$ & $0.7(0.9)$ & -2.608 & 0.0108 \\
\hline \multicolumn{5}{|c|}{ Somatic score } \\
\hline MDD & $9.3(2.4)$ & I I.0 (4.3) & 1.345 & 0.1862 \\
\hline MIND & $7.0(2.1)$ & $6.6(2.3)$ & -0.825 & 0.4119 \\
\hline NODEP & $4.4(2.0)$ & $2.3(1.9)$ & -4.861 & $<0.000 I^{*}$ \\
\hline \multicolumn{5}{|l|}{ Total score } \\
\hline MDD & $15.3(2.9)$ & I8.5 (4.7) & 2.385 & 0.0219 \\
\hline MIND & $11.9(3.0)$ & $11.9(2.6)$ & 0.030 & 0.9763 \\
\hline NODEP & $5.7(2.7)$ & $3.0(2.3)$ & -4.816 & $<0.000 I^{*}$ \\
\hline \multicolumn{5}{|l|}{ BDI } \\
\hline \multicolumn{5}{|c|}{ Psychic score } \\
\hline MDD & $11.9(5.1)$ & I $5.4(4.1)$ & $2.45 I$ & 0.0187 \\
\hline MIND & $7.8(3.7)$ & $8.3(3.2)$ & 0.574 & 0.5677 \\
\hline NODEP & $2.8(2.1)$ & I.4 (I.3) & -3.577 & $0.0006^{*}$ \\
\hline \multicolumn{5}{|c|}{ Somatic score } \\
\hline MDD & $8.9(2.5)$ & II.2(4.2) & 1.898 & 0.0649 \\
\hline MIND & $7.3(2.8)$ & $6.2(2.6)$ & -1.697 & 0.0939 \\
\hline NODEP & $4.0(2.3)$ & $1.8(1.5)$ & -4.991 & $<0.000 I^{*}$ \\
\hline \multicolumn{5}{|l|}{ Total score } \\
\hline MDD & $20.9(6.1)$ & $26.6(7.0)$ & 2.684 & 0.0105 \\
\hline MIND & I5.I (5.0) & I $4.5(4.5)$ & -0.573 & 0.5685 \\
\hline NODEP & $6.8(3.8)$ & $3.2(2.4)$ & -5.050 & $<0.000 I^{*}$ \\
\hline
\end{tabular}

Note: *Statistically significant differences after Bonferroni correction for multiple comparisons ( $P<0.05 / 18$ comparisons).

Abbreviations: BDI, Beck Depression Inventory; CS, control subjects; HDRS, Hamilton Depression Rating Scale; MDD, major depressive disorder; MIND, minor depressive disorder; NODEP, no depression; PD, Parkinson's disease; SD, standard deviation.

\section{Correlation analysis}

In the PD group, a significant positive correlation was found only between UPDRS-III and BDI-SOM subscore $(r=0.223$, $P=0.0345)$.

\section{Discussion}

In this study we examined the phenomenology of depression in PD patients. In particular, we analyzed the depressive profile of $\mathrm{PD}$ patients compared with that of patients affected by non-neurological medical illnesses, in order to control for the confounding effect of having a disabling illness.

Our results, after correction for multiple comparisons, showed that PD patients and CS as whole groups did not differ for severity of depressive symptomatology as measured by both the HDRS and BDI total score and PSY and SOM subscores. When we considered the frequency of specific symptoms of depression using the inclusive approach recommended by the NINDS/NIMH Work Group ${ }^{13}$ we found that PD patients experienced lower rates of worthlessness/ guilt and changes in appetite than CS. Our results are in line with previous papers describing reduced negative affective feelings of guilt and worthlessness, ${ }^{11-16}$ but are discordant with regard to changes in appetite. ${ }^{21}$ In fact, in PD patients, changes in appetite associated with weight loss had been previously described even before the onset of the illness or at the very early stage. Moreover, depression had been proposed as a contributor to appetite loss. In our PD sample we found reduced rates of loss of appetite, and one of the explanations we propose could be the effect of L-dopa treatment on the hypothalamus, ${ }^{33,34}$ a region associated with appetite regulation. ${ }^{35}$ In fact, it is reported that dopamine in the ventromedial hypothalamus is associated with stimulation of food intake. ${ }^{36}$ The L-dopa administration could increase the extracellular dopamine in the ventromedial hypothalamus with a restoration of food intake, ${ }^{37}$ thus contributing to maintain this aspect in equilibrium.

Results found in PD patients with MDD are sometimes different because they showed reduced severity of psychic depressive symptomatology using the HDRS (with a trend using the BDI), indicating that in well-structured and more severe clinical depression, such as MDD, the psychic dimension of depression may be less severe in PD patients when compared with CS. This finding is also reinforced by the fewer depressive symptoms of DSM-IV-TR found in PD patients with MDD in comparison with CS with MDD. On the other hand, in MIND patients we did not find any significant difference between PD and CS, probably because this diagnostic category of depression is less homogeneous and stable than MDD, thus impeding the capture of specific differences between these two groups of patients. Finally, only NODEP PD patients consistently reported increased severity of psychic, somatic, and total depressive symptoms in comparison with NODEP CS. In line with this, NODEP PD patients suffered from a greater number of DSMIV-TR depressive symptoms compared with NODEP CS. These results support the idea that in PD patients with subtle depressive symptoms but without formal diagnosis of mood disorder, the neurological symptoms could overlap the depressive phenomenology, leading to a more severe symptom expression. ${ }^{13}$ Accordingly, severity of motor symptoms measured by UPDRS-III was found to be associated with the somatic symptoms of depression, highlighting a relationship between the somatic symptoms of the neurological illness and the somatic symptoms of depression.

When we focused on groups with MDD, MIND, and NODEP separately, the frequency of the nine depressive 
Table 3 Differences in depressive symptoms as to the Diagnostic and Statistical Manual of Mental Disorders, 4th edition, text revision, between MDD, MIND, and NODEP PD and CS

\begin{tabular}{|c|c|c|c|c|c|}
\hline $\begin{array}{l}\text { Depressive } \\
\text { symptoms }\end{array}$ & $\begin{array}{l}\text { PD } \\
\text { n (\%) }\end{array}$ & $\begin{array}{l}\text { CS } \\
\text { n (\%) }\end{array}$ & $\chi^{2}$ & df & $\begin{array}{l}P \\
\text { uncorrected }\end{array}$ \\
\hline \multicolumn{6}{|c|}{ Sad mood (yes) } \\
\hline MDD & $14(93.3)$ & $26(96.3)$ & 0.187 & I & 0.6657 \\
\hline MIND & $33(84.6)$ & 32 (88.9) & 0.296 & & 0.5865 \\
\hline NODEP & I (2.2) & 0 & 0.814 & & 0.3669 \\
\hline \multicolumn{6}{|c|}{ Loss of interest/pleasure (yes) } \\
\hline MDD & $10(66.7)$ & $25(92.6)$ & 4.667 & 1 & 0.0308 \\
\hline MIND & $12(30.8)$ & $15(4 \mid .7)$ & 0.965 & & 0.3260 \\
\hline NODEP & 0 & 0 & & & \\
\hline \multicolumn{6}{|c|}{ Changes in appetite/weight (yes) } \\
\hline MDD & $4(26.7)$ & $13(48.1)$ & $\mathrm{I} .847$ & I & 0.1741 \\
\hline MIND & $4(10.3)$ & $5(13.9)$ & 0.234 & & 0.6286 \\
\hline NODEP & I (2.2) & 0 & 0.814 & & 0.3669 \\
\hline \multicolumn{6}{|c|}{ Changes in weight (yes) } \\
\hline MDD & $2(13.3)$ & $12(44.4)$ & 4.200 & I & 0.0404 \\
\hline MIND & $4(10.3)$ & $3(8.3)$ & 0.082 & & 0.7749 \\
\hline NODEP & I (2.2) & 0 & 0.814 & & 0.3669 \\
\hline \multicolumn{6}{|c|}{ Changes in appetite (yes) } \\
\hline MDD & $2(13.3)$ & II (40.7) & 3.389 & I & 0.0656 \\
\hline MIND & 0 & $3(8.3)$ & 3.385 & & 0.0658 \\
\hline NODEP & 0 & 0 & & & \\
\hline \multicolumn{6}{|c|}{ Sleep changes (yes) } \\
\hline MDD & $12(80)$ & $24(88.9)$ & 0.622 & I & 0.4302 \\
\hline MIND & $20(51.3)$ & $27(75)$ & 4.501 & & 0.0339 \\
\hline NODEP & $13(28.3)$ & $9(24.3)$ & 0.163 & & 0.6863 \\
\hline \multicolumn{6}{|c|}{ Early insomnia (yes) } \\
\hline MDD & $6(40)$ & $20(74.1)$ & 4.747 & I & 0.0293 \\
\hline MIND & $9(23.1)$ & $18(50)$ & 5.889 & & 0.0152 \\
\hline NODEP & II (23.9) & $4(10.8)$ & 2.378 & & 0.1231 \\
\hline \multicolumn{6}{|c|}{ Middle insomnia (yes) } \\
\hline MDD & $9(60)$ & $21(77.8)$ & 1.493 & I & 0.2217 \\
\hline MIND & $21(53.8)$ & $22(61.1)$ & 0.404 & & $0.525 I$ \\
\hline NODEP & II (23.9) & $15(40.5)$ & 2.635 & & 0.1045 \\
\hline \multicolumn{6}{|c|}{ Late insomnia (yes) } \\
\hline MDD & $8(53.3)$ & $21(77.8)$ & 2.696 & I & 0.1006 \\
\hline MIND & $14(35.9)$ & $20(55.6)$ & 2.919 & & 0.0875 \\
\hline NODEP & $12(26.1)$ & $10(27)$ & 0.009 & & 0.9232 \\
\hline \multicolumn{6}{|c|}{ Psychomotor changes (yes) } \\
\hline MDD & $2(13.3)$ & $3(I I . I)$ & 0.045 & I & 0.8313 \\
\hline MIND & $2(5.1)$ & 0 & 1.897 & & 0.1684 \\
\hline NODEP & $3(6.5)$ & 0 & 2.504 & & 0.1136 \\
\hline \multicolumn{6}{|c|}{ Agitation (yes) } \\
\hline MDD & 0 & $2(7.4)$ & 1.167 & I & $0.280 I$ \\
\hline MIND & 0 & 0 & & & \\
\hline NODEP & 0 & 0 & & & \\
\hline \multicolumn{6}{|c|}{ Slowness (yes) } \\
\hline MDD & $2(13.3)$ & I (3.7) & 1.348 & I & 0.2456 \\
\hline MIND & $2(5.1)$ & 0 & $\mathrm{I} .897$ & & 0.1684 \\
\hline NODEP & $3(6.5)$ & 0 & 2.504 & & 0.1136 \\
\hline \multicolumn{6}{|c|}{ Loss of energy (yes) } \\
\hline MDD & $15(100)$ & $26(96.3)$ & 0.569 & I & 0.4506 \\
\hline MIND & $35(89.7)$ & $28(77.8)$ & 1.994 & & 0.1579 \\
\hline NODEP & $29(63)$ & 17 (45.9) & 2.426 & & 0.1193 \\
\hline
\end{tabular}

(Continued)
Table 3 (Continued)

\begin{tabular}{|c|c|c|c|c|c|}
\hline $\begin{array}{l}\text { Depressive } \\
\text { symptoms }\end{array}$ & $\begin{array}{l}\text { PD } \\
\text { n (\%) }\end{array}$ & $\begin{array}{l}\text { CS } \\
\text { n (\%) }\end{array}$ & $\chi^{2}$ & df & $\begin{array}{l}P \\
\text { uncorrected }\end{array}$ \\
\hline \multicolumn{6}{|c|}{ Worthlessness/guilt (yes) } \\
\hline MDD & $5(33.3)$ & $18(66.7)$ & 4.325 & 1 & 0.0376 \\
\hline MIND & $3(7.7)$ & $6(16.7)$ & 1.428 & & 0.2321 \\
\hline NODEP & 0 & 0 & & & \\
\hline \multicolumn{6}{|c|}{ Changes in concentration (yes) } \\
\hline MDD & $13(86.7)$ & $23(85.2)$ & 0.017 & 1 & 0.8954 \\
\hline MIND & $16(4 I)$ & $10(27.8)$ & $\mathrm{I} .45 \mathrm{I}$ & & 0.2284 \\
\hline NODEP & $10(21.7)$ & $\mathrm{I}(2.7)$ & 6.464 & & 0.0110 \\
\hline \multicolumn{6}{|c|}{ Concentration deficits (yes) } \\
\hline MDD & $7(46.7)$ & $5(18.5)$ & 3.744 & 1 & 0.0530 \\
\hline MIND & $5(12.8)$ & $7(19.4)$ & 0.611 & & 0.4344 \\
\hline NODEP & $3(6.5)$ & I (2.7) & 0.652 & & 0.4194 \\
\hline \multicolumn{6}{|c|}{ Decisional incapability (yes) } \\
\hline MDD & $10(66.7)$ & $20(74.1)$ & 0.259 & I & 0.6106 \\
\hline MIND & II (28.2) & $6(16.7)$ & 1.422 & & 0.2331 \\
\hline NODEP & 7 (15.2) & 0 & 6.149 & & 0.0131 \\
\hline \multicolumn{6}{|c|}{ Suicide ideation (yes) } \\
\hline MDD & $2(13.3)$ & 0 & 3.780 & I & 0.0519 \\
\hline MIND & 0 & 0 & & & \\
\hline NODEP & 0 & 0 & & & \\
\hline
\end{tabular}

Note: *Statistically significant differences after Bonferroni correction for multiple comparisons ( $P<0.05 / 18$ comparisons).

Abbreviations: CS, control subjects; df, degrees of freedom; MDD, major depressive disorder; MIND, minor depressive disorder; NODEP, no depression; PD, Parkinson's disease.

symptoms listed in Criterion A of the DSM-IV-TR did not differ between the two groups of PD and CS.

Furthermore, our findings are not consistent with previous research about the somatic subtype of depression in PD, not only due to the differences in the clinical characteristics of the employed controls group and measures of depression used, but also because in our study we analyzed PD patients under stable dopaminergic therapy and during an "on" state. In fact, our results revealed that depressed PD patients did not exhibit a different somatic depressive profile compared with CS. In particular, depressed PD patients in our study did not report more somatic depressive symptoms, such as sleep disturbances and difficulty of concentration, as previously referred, ${ }^{9-11,38,39}$ rejecting the hypothesis that somatic depression in PD may be primarily related to the neurobiological mechanism of the disorder.

Strengths of our study are the stable dopaminergic therapy and assessment during the "on" phase. Moreover, the current study successfully addressed previous flaws in methodology by the addition of a relevant control group (ie, controlling for the impact of non-neurological chronic illnesses) that may be more comparable with PD in physical and psychological experiences. Another strength of our study is the thorough evaluation of both diagnosis and symptoms of depression 
using specific and validated scales, as well as a structured interview for diagnostic criteria.

One may criticize our study because we compared an unbalanced number of subjects in each category of depression: ie, MDD, MIND, and NODEP. This methodological confound could have resulted in weak statistical control. However, using this procedure we recruited a consecutive sample of individuals with depression, leaving preserved the clinical impact of depression in this population of individuals. Moreover, we employed a control group with different non-neurological medical illnesses in which the comorbidity could play an important role in depression prevalence, but, at the same time, this sample provides a clear picture of depression characteristics in elderly patients without neurological diseases. Nevertheless, future research should be dedicated to definitively confirm the hypotheses derived by our results.

\section{Conclusion}

Our findings support previous evidence that the profile of depressive symptoms in PD patients with mood disorders is quite comparable with that of patients suffering from other disabling non-neurological medical illnesses, although PD patients with MDD exhibited fewer psychic symptoms. Conversely, the evidence that nondepressed PD patients showed more severe depressive symptoms than nondepressed CS suggests that increased severity of depressive symptoms in PD with no comorbid depressive disorders could be secondary to, or influenced by, neurological symptoms, and could result from loss of endogenous neurotransmitters such as dopamine, serotonin, and norepinephrine, which are described in PD. ${ }^{40-42}$ Therefore, future research should clarify the question about the nature of depression in $\mathrm{PD}$, which still remains uncertain and inhomogeneous among the three groups of MDD, MIND, and NODEP, in order to help clinicians to form diagnostic or therapeutic decisions. Moreover, the diagnostic process of depression in PD should take into consideration the possible overlap between neurological and depressive symptoms. Thus, an integrated neuropsychiatric approach, in which biological and psychological processes are considered to be thoroughly intertwined, should be encouraged in PD.

\section{Acknowledgments}

The work was supported by the Italian Ministry of Health (IMH; RC 09-10-11-12 and RF 07-08).

\section{Disclosure}

The authors report no conflicts of interest in this work.

\section{References}

1. Starkstein SE, Mayberg HS, Leiguarda R, Preziosi TJ, Robinson RG. A prospective longitudinal study of depression, cognitive decline, and physical impairments in patients with Parkinson's disease. J Neurol Neurosurg Psychiatry. 1992;55(5):377-382.

2. Stern Y, Marder K, Tang MX, Mayeux R. Antecedent clinical features associated with dementia in Parkinson's disease. Neurology. 1993;43(9):1690-1692.

3. Tandberg E, Larsen JP, Aarsland D, Cummings JL. The occurrence of depression in Parkinson's disease. A community-based study. Arch Neurol. 1996;53(2):175-179.

4. Tandberg E, Larsen JP, Aarsland D, Laake K, Cummings JL. Risk factors for depression in Parkinson disease. Arch Neurol. 1997;54(5): 625-630.

5. Troster AI, Stalp LD, Paolo AM, Fields JA, Koller WC. Neuropsychological impairment in Parkinson's disease with and without depression. Arch Neurol. 1995;52(12):1164-1169.

6. Hobson P, Holden A, Meara J. Measuring the impact of Parkinson's disease quality of life questionnaire. Age Ageing. 1999;28(4): 341-346.

7. Schrag A, Jahanshahi M, Quinn N. What contributes to quality of life in patients with Parkinson's disease? J Neurol Neurosurg Psychiatry. 2000;69(3):308-312.

8. Schrag A. Quality of life and depression in Parkinson's disease. J Neurol Sci. 2006;248(1-2):151-157.

9. Ehmann TS, Beninger RJ, Gawel MJ, Riopelle RJ. Depressive symptoms in Parkinson's disease: a comparison with disabled control subjects. J Geriatr Psychiatry Neurol. 1990;3(1):3-9.

10. Erdal KJ. Depressive symptom patterns in patients with Parkinson's disease and other older adults. J Clin Psychol. 2001;57(12):1559-1569.

11. Gotham A, Brown R, Marsden C. Depression in Parkinson's disease: a quantitative and qualitative analysis. J Neurol Neurosurg Psychiatry. 1986;49(4):381-389.

12. Lieberman A. Depression in Parkinson's disease - a review. Acta Neurol Scandinav. 2006;113(1):1-8.

13. Marsh L, McDonald WM, Cummings J, Ravina B; NINDS/NIMH Work Group on Depression and Parkinson's Disease. Provisional diagnostic criteria for depression in Parkinson's disease: Report of an NINDS/ NIMH Work Group. Mov Disord. 2006;21(2):148-158.

14. Starkstein SE, Preziosi TJ, Forrester AW, Robinson RG. Specificity of affective and autonomic symptoms of depression in Parkinson's disease. J Neurol Neurosurg Psychiatry. 1990;53(10):869-873.

15. Starkstein SE, Merello M, Jorge R, et al. A validation study of depressive syndromes in Parkinson's disease. Mov Disord. 2008;23(4):538-546.

16. Starkstein SE, Dragovic M, Jorge R, et al. Diagnostic criteria for depression in Parkinson's disease: a study of symptom patterns using latent class analysis. Mov Disord. 2011;26(12):2239-2245.

17. Lou JS, Kearns G, Oken B, Sexton G, Nutt J. Exacerbated physical fatigue and mental fatigue in Parkinson's disease. Mov Disord. 2001; 16(2):190-196.

18. Mergl R, Mavrogiorgou P, Hegerl U, Juckel G. Kinematic analysis of emotionally induced facial expressions: a novel tool to investigate hypomimia in patients suffering depression. J Neurol Neurosurg Psychiatry. 2005;76(1):138-140.

19. American Psychiatric Association. Diagnostic and Statistical Manual of Mental Disorders, 4th ed, text revision (DSM-IV-TR). Washington, DC: American Psychiatric Association; 2000.

20. Leentjens AF, Verhey FR, Lousberg R, Spitsbergen H, Wilmink FW. The validity of the Hamilton and Montgomery-Asberg depression rating scales as screening and diagnostic tools for depression in Parkinson's disease. Int J Geriatr Psychiatry. 2000;15(7):644-649.

21. Leentjens AF, Marinus J, Van Hilten JJ, Lousberg R, Verhey FR. The contribution of somatic symptoms to the diagnosis of depressive disorder in Parkinson's disease: a discriminant analytic approach. J Neuropsychiatry Clin Neurosci. 2003;15(1):74-77. 
22. Lyness JM, Bruce ML, Koenig HG, et al. Depression and medical illness in late life: report of a symposium. JAm Geriatr Soc. 1996;44(2): 198-203.

23. Hughes AJ, Daniel SE, Lees AJ. Improved accuracy of clinical diagnosis of Lewy body Parkinson's disease. Neurology. 2001;57(8): 1497-1499.

24. Folstein M, Folstein SE, McHugh PR. Mini-Mental State: a practical method for grading the cognitive state of patients for the clinicians. J Psychiatr Res. 1975;12(3):189-198.

25. Fahn S, Elton RL. Members of the UPDRS Development Committee. Unified Parkinson's Disease Rating Scale. In: Fahn S, Marsden CD, Calne D, Goldstein M, editors. Recent Developments in Parkinson's Disease. Florham Park, NJ: MacMillan Health Care Information; 1987: 153-304.

26. Langston JW, Widner H, Goetz CG, et al. Core assessment program for intracerebral transplantations (CAPIT). Mov Disord. 1992;7(1):2-13.

27. Beck A, Steer RA. Beck Depression Inventory Manual. San Antonio, TX: The Psychological Corporation; 1987.

28. Hamilton M. A rating scale for depression. J Neurol Neurosurg Psychiatry. 1960;23(1):56-62.

29. Beck AT, Steer RA, Garbin MG. Psychometric properties of the Beck Depression Inventory: twenty-five years of evaluation. Clin Psychol Rev. 1988;8(1):77-100.

30. Koenig HG, Cohen HJ, Blazer DG, Ranga Rama Krishnan K, Sibert TE. Profile of depressive symptoms in younger and older medical inpatients with major depression. J Am Geriatr Soc. 1993;41(11):1169-1176.

31. Spalletta G, Troisi A, Saracco M, Ciani N, Pasini A. Symptom profile, Axis II comorbidity and suicidal behaviour in young males with DSMIII-R depressive illnesses. J Affect Disord. 1996;39(2):141-148.

32. First MB, Spitzer RL, Gibbon M, Williams JBW. Structured clinical interview for DSM-IV-TR Axis I disorders, research version, patient edition (SCID-I/P). New York, NY: Biometrics Research, New York State Psychiatric Institute; 2002.
33. Gasparini M, Spinnler H. Fattening of parkinsonians: a hypothalamic side effect of L-dopa? Med J Aust. 1975;2(15):617.

34. Szczypka MS, Rainey MA, Palmiter RD. Dopamine is required for hyperphagia in Lep(ob/ob) mice. Nat Genet. 2000;25(1):102-104.

35. Morton GJ, Cummings DE, Baskin DG, Barsh GS, Schwartz MW. Central nervous system control of food intake and body weight. Nature. 2006;443(7109):289-295

36. Fetissov SO, Meguid MM, Chen C, Miyata G. Synchronized release of dopamine and serotonin in the medial and lateral hypothalamus of rats. Neuroscience. 2000;101(3):657-663.

37. Alam MR, Yoshizawa F, Sugahara K. L-dopa induced extracellular dopamine increases in the ventromedial hypothalamus affects food intake by chickens on a lysine-free diet. Neurosci Lett. 2011;495(2): 126-129.

38. Merschdorf U, Berg D, Csoti I, et al. Psychopathological symptoms of depression in Parkinson's disease compared to major depression. Psychopathology. 2003;36(5):221-225.

39. Schiffer RB, Kurlan R, Rubin A, Boer S. Evidence for atypical depression in Parkinson's disease. Am J Psychiatry. 1988;145(8):1020-1022.

40. Beucke JC, Uhl I, Plotkin M, et al. Serotonergic neurotransmission in early Parkinson's disease: a pilot study to assess implications for depression in this disorder. World J Biol Psychiatry. 2010;11(6): 781-787.

41. Chaudhuri KR, Schapira A. Non-motor symptoms of Parkinson's disease: dopaminergic pathophysiology and treatment. Lancet Neurol. 2009;8(5):464-474.

42. McDonald WM, Richard IH, DeLong MR. Prevalence, etiology, and treatment of depression in Parkinson's disease. Biol Psychiatry. 2003;54(3):363-375.
Neuropsychiatric Disease and Treatment

\section{Publish your work in this journal}

Neuropsychiatric Disease and Treatment is an international, peerreviewed journal of clinical therapeutics and pharmacology focusing on concise rapid reporting of clinical or pre-clinical studies on a range of neuropsychiatric and neurological disorders. This journal is indexed on PubMed Central, the 'PsycINFO' database and CAS.

\section{Dovepress}

The manuscript management system is completely online and includes a very quick and fair peer-review system, which is all easy to use. Visit http://www.dovepress.com/testimonials.php to read real quotes from published authors. 